\title{
Technology-Embedded Educational Policy: Mediation Effects of the Use of Virtual Learning Influence on Learner Satisfaction
}

\author{
Narain Das (corresponding author) \\ School of Public Affairs, University of Science and Technology of China, China \\ E-mail: narain_das1990@hotmail.com \\ Sunguh Kenneth Khawandiza \\ School of Public Affairs, University of Science and Technology of China, China
}

Binesh Sarwar

School of Public Affairs, University of Science and Technology of China, China

Arslan Ahmed

School of Public Affairs, University of Science and Technology of China, China

Shah Hassan

School of Public Affairs, University of Science and Technology of China, China

Received: July 29, 2018

doi:10.5296/jet.v6i1.13856
Accepted: August 14, $2018 \quad$ Published: December 31, 2018

URL:http://dx.doi.org/10.5296/jet.v6i1.13856

\begin{abstract}
While research on the use of technology to enhance learner satisfaction has received so much consideration from scholars, only limited studies have examined the effects and usefulness of virtual learning about learner satisfaction. In this study, Technology Adoption Model (TAM) and Task-Technology Fit theory (TTF) have been integrated to explore how virtual learning plays a significant role specifically by testing the mediation effects that virtual learning has on the relationship between peer interaction, perceived usefulness, ease of use and learner satisfaction. The Structural Equation Modeling (SEM) technique was used to analyze the data whereby both Explanatory Factor Analysis (EFA) and a Confirmatory Factor Analysis (CFA) were performed on the variables. The results indicate that all hypotheses have been confirmed by providing significant positive relationships between the variables and more importantly, virtual learning plays a highly significant role in promoting learner satisfaction. It is concluded that higher learning institutions should incorporate virtual learning methods to motivate learners in order to encourage satisfaction hence ensuring higher performance.
\end{abstract}

Keywords: Virtual Learning, Learner Satisfaction, Usefulness, Ease of Use, Peer Interaction 


\section{Introduction}

Virtual Learning is the use of media transmission innovation to convey data for instruction for education guidance. Through the advancement of knowledge and communication technology improvement, Virtual Learning is rising as the worldview of present-day education. Learning strategies have transformed; they have moved from the traditional instructing model to a student-focused model that includes the student in a functioning job (Garris, Ahlers, \& Driskell, 2002). At the present techniques for learning are moving from learning by listening in to learning by action.

The enormous points of interest of Virtual Learning incorporate freeing connections among students and students or students and teachers, or, from restrictions of geographic location and time through the asynchronous and synchronous learning system model (Katz, 2000, 2002; Trentin, 1997). Online courses endeavor to make knowledge more open and perhaps more helpful by expelling the requirements of time and geography (Berge \& Collins, 1995; Horvitz, 2007; Sun, Tsai, Finger, Chen, \& Yeh, 2008). Virtual learning's qualities satisfy the necessities for learning in an advanced society and furthermore have made a significant interest for virtual gaining from organizations and foundations of higher education (Goodhue \& Thompson, 1995).

Task-Technology Fit Theory proposed that information technology is helpful to the performance and satisfaction at work only when the technology is accepted and applied by users and when the technology fits in the assignments it supports. A more elevated level of individual performance and fulfillment can recommend enhanced efficacy and effectiveness (Bukie, 2015).

In this modern era, while Technology builds up, the learning model must keep on changing to address the issues of different sorts of students. The essential points of interest in Technology based learning situations are adaptability and henceforth, prompting learning satisfaction. Satisfaction is defined as a person's attitude or feelings associated with various factors that are affecting a particular situation (Bailey \& Pearson, 1983). Student satisfaction is more accurately conceptualized as students' perception developed from the perceived value of education and experience gained at an educational institute. In past research, scholars have approved that virtual learning structure enhances students learning and their satisfaction level (Astin, 1993).

This study examined the learner satisfaction from the use of virtual Learning technology environment by using the Technology Adoption Model (TAM). In previous studies, TAM was used to determine the effects of adopting new technologies. Inside the next section, past studies related writing and factors impacting students' satisfaction in virtual Learning conditions are discussed. Based on the designed research a coordinate model proposed by this study is described and analyzed. At last, the outcomes are analyzed and presented.

\section{Theoretical Framework}

\subsection{Perceived Usefulness and Perceived Ease of use}

Various researchers from information and technology system have acknowledged the 
essential factors dealing with virtual learning. Along with the technology acceptance model (TAM) (Davis, 1989; Sarwar, Zulfiqar, Aziz, \& Chandia, 2018; Sun et al., 2008) of those discussions have partially contributed to considerate the online learning and learner satisfaction. Such kind of models specially tends to focus on information and technology. The TAM is mainly focused on the building that "perceived usefulness" and Perceived ease of use are strong motivational variables to believe and latest use of advanced technologies. Perceived Usefulness is discussed as "the amount to which a individual consider that utilizing a specific framework would improve his/her satisfaction and work performance" (Davis, 1989).

It represents the meaningful outcomes derived from the characteristics of technology being utilized (Rauniar, Rawski, Yang, \& Johnson, 2014). On the other side perceived ease of use is discussed as "the degree in which a people considers that utilizing a particular system would be free of any mental and physical exertion' (Davis, 1989). further studies also posit that the use of information technology tools dramatically depends on its perceived usefulness and perceived ease of use (Venkatesh et al., 2003), that great advantage of online learning over traditional face-to-face teaching (Piccoli, Ahmad, \& Ives, 2001) whereas concerns arising from its use include time and location, work intensiveness, and material resources engaged with running virtual learning situations. Educational performance and learning of scholars were additionally estimated by some differences in regards to enhanced creativeness and communication skills because of the usefulness and level of easiness of use that the internet learning tools possess (Kabilan, Ahmad, \& Abidin, 2010). Based on the previous discussion, for this research we propose the following hypothesis:

H1: There is a significant positive relationship between perceived usefulness and Virtual learning.

H2: There is a significant positive relationship between Perceived ease of use and Virtual learning.

\subsection{Peer Interaction}

In the education context, peer discussion or peer interaction has been emphasized to encourage learning. For instance, in the modern period, peer review or peer tutoring has gained concentration significantly between learners for the development of students learning (Liu \& Tsai, 2005; Tsai, Lin, \& Yuan, 2002). Further research, pointed out that it is proved discussion gives an opportunity to clarify once own idea, thought and viewpoint or self-demonstration in response to advice from others.

Accordingly, (CMC) computer-mediated communication performs a vital role in internet-based discussion or solving the problems for academic purposes. Computer-mediated communication systems, like computer-based conferencing, electronic mail, have been broadly used to support online problem-solving or peer discussion (Hakkarainen \& Palonen, 2003). Based on the above discussion, peer interaction among students consists of processes of communication, where students can share information and knowledge about the outline of course contents and information. Students can get more advantage in the different ways, like boost understanding, socio-emotional support under the working in small groups, and 
learning inside an organized and encouraging environment (Jucks, Paechter, \& Tatar, 2003). Mutual support and group structure feelings are associated with learners' commitment to teamwork, an inspiration to involve you in a web-based learning system, and academic lessons satisfaction (Concannon, Flynn, \& Campbell, 2005). Based on the previous discussion, for this research we propose the following hypothesis:

H3: There is a significant positive relationship between Peer interaction and Virtual learning.

\subsection{Virtual Learning}

Virtual Learning is the utilization of communication technology to convey knowledge and information for learning and training. With the fast advancement of data and communication technology improvement, Virtual Learning is developing as the concept of modern education. Virtual Learning, a common term for information, training and education has been emphasizes assemble skills and knowledge (Iqbal \& Ahmad, 2010), a method that evolved from distance-based education which allows to learners, learning, and knowledge sharing without any restriction of time or geographical location (Qureshi, Ilyas, Yasmin, \& Whitty, 2012). It is primarily distance learning or web-based learning system that makes knowledge and information accessible to learners and disregards of time boundary or space closeness. According to Katz (2000, 2002), virtual learning incorporates liberating associations among students and instructors, or students and students, from restrictions of time and geographic location through the asynchronous and synchronous learning system model. Furthermore, Qureshi et al. (2012) also discussed in his research, posited that this method evolved from distance-based education which allows information, knowledge sharing and learning without the limitation of time or space. In the modern technological era, it has become an educational need to adopt new technologies in education as seen in the above discussion for instance virtual learning. Virtual learning's attributes complete the needs for learning in an advanced society and have made popularity for internet learning from organizations and establishments of higher education. There are so many organizations around the world who are offering online education (Sun et al., 2008), for instance, Massachusetts Institute of Technology (MIT) try to offer online all of its courses and full online degree programs has sent a signal to foundations on the vital significance of virtual Learning (Wu, Tsai, Chen, \& Wu, 2006). Some researchers describe virtual learning as distance education or web-based learning system; virtual learning that makes knowledge or information offered to learners and students disregards limitation of time or place closeness. Though internet-based learning has benefit over traditional face-to-face learning (Piccoli et al., 2001), its fundamental concerns incorporate time, work seriousness, and material assets associated with running virtual Learning system.

H4: There is a significant positive relationship between Virtual learning and learner satisfaction.

\subsection{Learner Satisfaction}

As the new technologies develop, the model of learning and teaching must keep on changing to meet up the requirements of various types of students, learners, and the instructor. The primary benefit of new technology-based learning conditions is adaptability and consequently, 
student's learning satisfaction. According to Martínez-Torres et al. (2008), the bright, reasonable message is that customary frameworks must be changed to end up substantially more open and adaptable, with the goal that students can have singular learning pathways, appropriate to their requirements and premiums, and ultimately take benefit of equal opportunities all through their learning period and lives. In recent years, web-based learning has developed in popularity as a learning model, and whether the plan of a web-based learning framework satisfies the requirements of students and learners straightforwardly influences their learning satisfaction. Since web-based learning is getting much attention in recent years, the model of this research is ongoing. It includes points, for example, the information technology abilities of virtual learning (Piccoli et al., 2001), the impact of changes to internet-based learning teaching models evaluation and examination of web-based learning to improve learning satisfaction (Lai, Luo, Zhang, Huang, \& Rozelle, 2015). Arbaugh (2002) recognized the apparent adaptability of the medium, ease of use, usefulness, media diversity, earlier instructor knowledge, virtual immediacy behaviors, and communication as the essential vital factors that are affecting student and learner's satisfaction in web-based learning conditions.

\section{Research Methodology and Data Collection}

This research employs structural equation modeling (SEM) approach to expand and prove the research model and to demonstrate the relationship between five constructs (Figure 1). This research measures the effect of peer interaction, perceived ease of use, perceived usefulness from virtual learning environment which outcome in learner satisfaction using TAM. To carry out the statistical analysis, the data of this research were collected from the students in public universities of Pakistan, who are fully engaged in virtual learning and distributed across different provinces of Pakistan. The provinces covered under this research include Punjab, Khyber Pakhtunkhwa (kpk), and Islamabad the capital city of Pakistan, which are home to the most significant number of universities. Prominent public Pakistani universities include the Allama Iqbal Open University, Virtual University of Pakistan, and Bahauddin Zakariya University. 470 questionnaires were circulated among students using the mobile applications namely Whatsapp and Wechat, out of which 350 questionnaires were found correctly filled. The questionnaire was adjusted from various research articles, for example, perceived ease of use and perceived usefulness was adjusted from previous examinations, who have conclusively settled their reliability and validity (Davis, 1989).

Similarly, the items for peer interaction were adopted (Arbaugh, 2002). While the items for virtual learning were adopted from (Pituch \& Lee, 2006; Venkatesh \& Davis, 2016) and learner satisfaction (Arbaugh, 2000; Sun et al., 2008), with words and sentences modifications by the present study. Seven Likert scales are used where one represents strongly agrees, four neutral, and seven strongly disagree. A concise outline was also given to respondents about the research reason toward the beginning of the survey to build up their underlying comprehension. The respondents were also ensured that the information accumulation would be utilized for an educational purpose that is the reason they were not requested to specify about their contact information. 


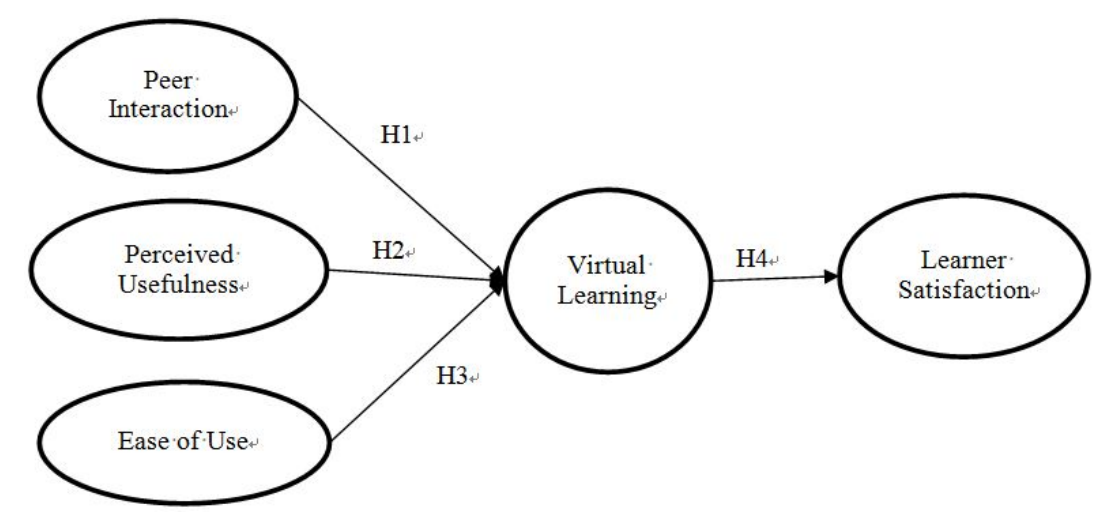

Figure 1. Integrated research model based on TAM and TTF

\section{Data Analysis}

For this research information was collected from the classified respondents, according to gender, education, and students who are learning in an online learning environment. Gender was classified as female and male and; respondents were 60.3 and $39.7 \%$, in that order. Level of Education classified as undergraduate, post-graduate, and Ph.D. respondents were 7.7, 33.4, 58.9, and 12.6, correspondingly, and respondents of the educational level were 22.9, 47.1, 30.0, shows in Table 1. All these respondents enrolled in web-based learning.

In regards to the examination of measurements, we tested our research model by applying a structural equation modeling (SEM) approach, using the computer software LISREL 8.80 (Jöreskog \& Sörbom, 1993). In this research, the primary exploratory factor analysis using SPSS was used to deal with measurement reduction of items. In order to test the data validity, liability test was run. Different least amount sample sizes for the SEM approach have suggested. For example, Hu \& Bentler (1999) recommended a lowest sample size of 100, while Anderson, James C., Gerbing David, (1988) suggested a least amount sample size of 200 and Gefen, Straub, \& Boudreau (2000) reported that the standard of sample size for such kind of research using LISREL was 249 (minimum 41, maximum 451). For that reason, the sample size of 350 in this research was considered adequate. We used LISREL 8.80 which has been known to be an influential tool that uses the confirmatory factor analysis, regression, and structural model at the similar time to estimate the dimension model and structural model (Jöreskog, 2004). For this type of research, the threshold levels for Cronbach's alpha, composite reliability, and average variance extracted (AVE) should be 0.7, 0.7, and 0.5, according to the standard criteria in previous research (Hulland, 1999; Scholle et al., 2008; Wiegel, Meston, \& Rosen, 2005). As seen in Table 2 and Table 3, composite reliability (CR) and Cronbach's alpha values are higher than .7, and AVE values for all constructs are higher than .5 and that the correlations between variables are within acceptable range. 
Table 1. Demographic information of the respondents

\begin{tabular}{llll}
\hline Measures & & Frequency & Percentage (\%) \\
\hline Gender & Male & 211 & 60.3 \\
Age & Female & 139 & 39.7 \\
& Below 20 & 27 & 7.7 \\
Education Level & $20-24$ & 117 & 33.4 \\
& $25-30$ & 206 & 58.9 \\
& Undergraduate & 80 & 22.9 \\
& Masters & 165 & 47.1 \\
& PhD & 105 & 30.0 \\
\hline
\end{tabular}

Table 2. Confirmatory Factor Analysis (CFA)

\begin{tabular}{|c|c|c|c|c|c|}
\hline Constructs & & Factor loading & $\begin{array}{l}\text { Cronbach } \\
\text { Alpha }\end{array}$ & AVE & $\mathrm{CR}$ \\
\hline Peer Interaction & PI1 & 0.873 & 0.952 & 0.688 & 0.952 \\
\hline & PI2 & 0.877 & & & \\
\hline & PI3 & 0.868 & & & \\
\hline & PI4 & 0.834 & & & \\
\hline & PI5 & 0.753 & & & \\
\hline & PI6 & 0.817 & & & \\
\hline & PI7 & 0.785 & & & \\
\hline & PI8 & 0.856 & & & \\
\hline & PI9 & 0.793 & & & \\
\hline Perceived usefulness & PU1 & 0.930 & 0.948 & 0.782 & 0.935 \\
\hline & PU2 & 0.938 & & & \\
\hline & PU3 & 0.849 & & & \\
\hline & PU4 & 0.814 & & & \\
\hline Ease of Use & EU1 & 0.764 & 0.934 & 0.666 & 0.888 \\
\hline & EU2 & 0.894 & & & \\
\hline & EU3 & 0.811 & & & \\
\hline & EU4 & 0.791 & & & \\
\hline Virtual Learning & VL1 & 0.864 & 0.948 & 0.720 & 0.939 \\
\hline & VL2 & 0.851 & & & \\
\hline & VL3 & 0.835 & & & \\
\hline & VL4 & 0.844 & & & \\
\hline & VL5 & 0.851 & & & \\
\hline & VL6 & 0.847 & & & \\
\hline Learner satisfaction & S1 & 0.750 & 0.952 & 0.667 & 0.947 \\
\hline & $\mathrm{S} 2$ & 0.856 & & & \\
\hline & S3 & 0.846 & & & \\
\hline & S4 & 0.851 & & & \\
\hline & S5 & 0.771 & & & \\
\hline & S6 & 0.819 & & & \\
\hline & S7 & 0.794 & & & \\
\hline & S8 & 0.785 & & & \\
\hline & S9 & 0.867 & & & \\
\hline
\end{tabular}

Extraction Method: Maximum Likelihood. Rotation Method: Promax with Kaiser Normalization. 
Table 3. Means, standard deviations, correlations, and AVE Square-root

\begin{tabular}{llllllll}
\hline Constructs & Mean & $(\mathrm{SD})$ & PI & PU & EU & VL & S \\
\hline PI & 2.58 & $(0.778)$ & $\mathbf{0 . 8 2 9}$ & & & & \\
PU & 2.05 & $(0.987)$ & .186 & $\mathbf{0 . 8 8 4}$ & & & \\
EU & 1.83 & $(0.875)$ & .381 & .550 & $\mathbf{0 . 8 1 6}$ & & \\
VL & 1.87 & $(0.824)$ & .377 & .465 & .505 & $\mathbf{0 . 8 4 9}$ & \\
S & 1.82 & $(0.723)$ & .308 & .578 & .657 & .655 & $\mathbf{0 . 8 1 6}$ \\
\hline
\end{tabular}

Note. $\mathrm{N}=350$. All correlations are significant at $\mathrm{p}<0.01$. Values on the diagonal represent AverageVariance Extracted (AVE).

SEM has been regarded as a cross-discipline research instrument hence has now developed into vital techniques used by scholars to validate their research outcomes (O'Rourke \& Hatcher, 2013). To determine the model fitness, researchers are required to inspect fitness indices including chi-square, the goodness of fit index (GFI), adjusted goodness of fit index (AGFI), comparative fit index (CFI), and root mean square root error of approximation (RMSEA). According to prior research, for the goodness of model fit, the accepted value for chi-square no higher than 5.0 depending upon the sample size (Schreiber, Stage, King, Nora, \& Barlow, 2006). RMSEA accepted value is to be under 0.10 . Indices values have to be greater than 0.90 for a satisfactory fit. Different researchers suggested that for NFI, IFI, and CFI indices values can be higher than 0.85. For this research, the SEM method was completed by utilizing LISREL8.80 whereby CFA was done to quantify the model goodness-of-fit utilizing different indices. According to the previously mentioned literature, indices figured for this investigation demonstrate the proper goodness-of-fit for both our measurement and a structural model where all values of chi-square, GFI, AGFI, CFI, NFI, NNFI, IFI, and RMSEA are inside adequate range as shown in Tables 4 and 5 respectively.

Table 4. Measurement Model

\begin{tabular}{lllllllll}
\hline Fit indices & $\mathrm{x}^{2} / \mathrm{df}$ & RMSEA & GFI & AGFI & CFI & NFI & NNFI & IFI \\
\hline Recommended value & $<3$ & $<0.08$ & $>0.90$ & $>0.80$ & $>0.90$ & $>0.90$ & $>0.90$ & $>0.90$ \\
Value in this study & 1.980 & 0.053 & 0.86 & 0.84 & 0.99 & 0.98 & 0.98 & 0.99 \\
\hline
\end{tabular}

Table 5. Structural Model

\begin{tabular}{lllllllll}
\hline Fit indices & $\mathrm{x}^{2} / \mathrm{df}$ & RMSEA & GFI & AGFI & CFI & NFI & NNFI & IFI \\
\hline Recommended value & $<3$ & $<0.08$ & $>0.80$ & $>0.80$ & $>0.90$ & $>0.90$ & $>0.90$ & $>0.90$ \\
Value in this study & 2.172 & 0.058 & 0.85 & 0.83 & 0.98 & 0.97 & 0.98 & 0.98 \\
\hline
\end{tabular}

\subsection{Hypothesis Testing and Effects}

After suggesting the validity of the measurement model, we explored the hypotheses relationship as pursues; proposed hypotheses tested. The figure demonstrates the path 
analysis by utilizing LISREL 8.80 . The outcomes demonstrate that peer interaction $(\beta=0.190$, $\mathrm{p}<0.01)$ perceived usefulness $(\beta=0.250, \mathrm{p}<0.001)$, and perceived ease of use $(\beta=0.350$, $\mathrm{p}<0.001$ ) all have significant positive association with virtual learning. These result support $\mathrm{H} 1, \mathrm{H} 2$, and $\mathrm{H} 3$, respectively Hypothesis 4 recommended a significant positive association between virtual learning and students satisfaction and was also supported with $(\beta=0.710$, $\mathrm{p}<0.001)$. Outcomes show that all proposed hypothesis supported and significant positive relationship.

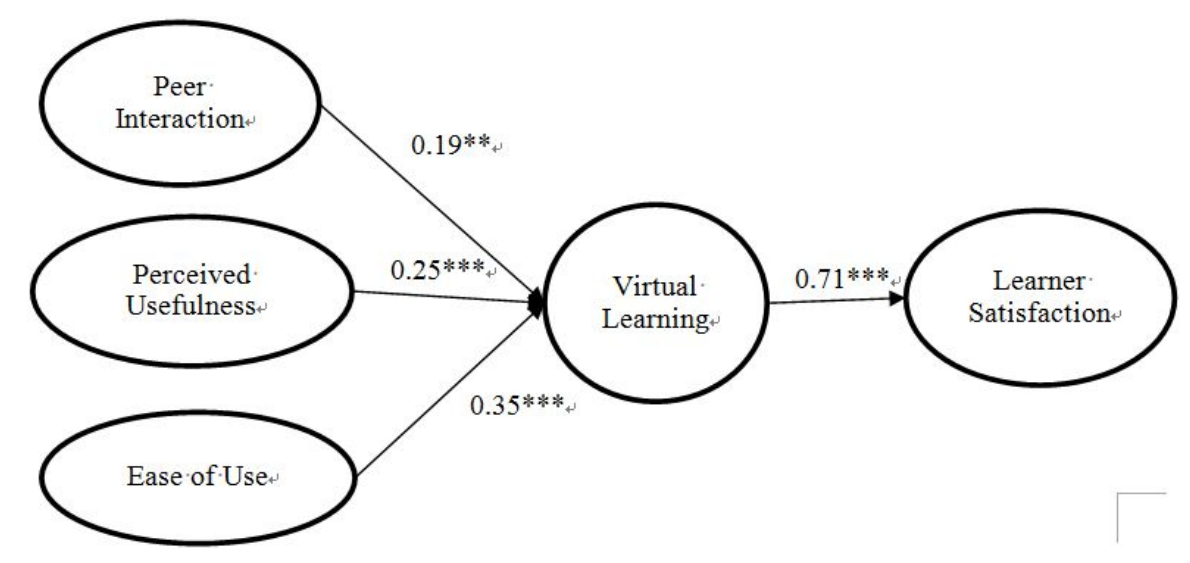

Figure 2. Path Diagram $(* * *-\mathrm{p}<0.001 ; * *-\mathrm{p}<0.01)$

\section{Conclusion, Implications and Future Research}

Virtual Learning is an option in contrast to traditional face-to-face learning. Various foundations around the globe implement Virtual learning framework to meet learners' desires and satisfaction, particularly those of non-traditional learners simply like Massachusetts Institute of Technology tried to present virtually the majority of its online courses has sent a sign to institutes on the purposeful significance of Virtual Learning. Since Virtual Learning is led utilizing the Internet and the learning condition turns out to be more easy to use. Learners' first perceived ease of use and perceived usefulness with technology-based Learning can increase learner satisfaction in the virtual learning system. This study recognizes such factors affecting students' satisfaction. An incorporated model created from past research comprising of five components introduced to guide research.

At first, the fundamental purpose of this research is to look at the effects of Virtual Learning on the learning satisfaction of the learners. As traditional techniques of teaching concentrated on class lectures, giving lectures on theories and ideas, virtual learning enables students to work anyplace disregards of time and geographical location. Even though web-based learning has benefited over traditional face-to-face education (Piccoli et al., 2001), although concerns emerging from its use incorporate time and place, work seriousness, and material assets associated with running virtual learning situations. Although the concerns research by Gregory et al. (2014) and Selwyn (2007) suggested that learners were observed to be better inspired and satisfied to learn and make more innovative activities $s$ through using rising educational technologies. 


\section{Macrothink Institute ${ }^{\mathrm{TM}}$}

This study was performed on students who had a place with various fields to determine the student fulfillment of the students with the Virtual Learning framework. The consequence of the study analyzed whether student learning satisfaction enhances by using Virtual Learning.

Though this study represents a specific and systematic attempt to integrate components of Virtual Learning. The study proposes an incorporated model covering an assortment of components impacting virtual learners' satisfaction. This research contributes to the offered literature by joining the Technology Adoption Model (TAM) system in combination with the Task-Technology Fit hypothesis (TTF) to improve the thoughtful and satisfaction of virtual learning.

Findings of this research indicate that peer interaction, usefulness and ease of use; have a significant positive relationship with virtual learning. These outcomes demonstrate that virtual learning has gained popularity among individuals due to its ease, disregards of time and geographical location. Also, this is simply quantitative research the information for this research gathered through review surveys, for information accumulation from various public virtual universities of Pakistan. Future research could be led with other factors of virtual learning on, different level of students like college or school, and different areas. The current research also suggested that future research integrate different variables influencing virtual learning, such as course quality, internet, and technical quality or diversity in assessment, to measure their effects on learner satisfaction.

\section{References}

Arbaugh, J. B. (2000). Virtual Classroom characteristics and student satisfaction with internet-based MBA courses. Journal of Management Education, 24(1), 32-54.

Arbaugh, J. B. (2002). Managing the on-line classroom. A study of technological and behavioral characteristics of web-based MBA courses. Journal of High Technology Management Research, 13(2), 203-223.

Astin, A. (1993). Student. Journal of Student Affairs, 3.

Bailey, J. E., \& Pearson, S. W. (1983). Development of a Tool For Measuring and Analyzing Computer User Satisfaction. USA: Management Science.

Berge, Z., \& Collins, M. (1995). Introduction: From marks in the sand to computer conferencing via fiber optics. Computer-Mediated Communication and the Online Classroom in Distance Learning, 2(4), 1-8. Retrieved from http://www.december.com/cmc/mag/1995/apr/berge.html

Bukie, F. (2015). Task Technology Fit and Lecturers Performance Impacts: The Technology Utilization, Satisfaction and Performance (TUSPEM) Dimension. International Journal of Computer Science Issues, 12(3), 232-239.

Concannon, F., Flynn, A., \& Campbell, M. (2005). Benefits of E-Learning, 36(3).

Davis, F. (1989). Perceived usefulness, perceived ease of use, and user acceptance of information technology. MIS Quarterly, 13(3), 319-340. 
Garris, R., Ahlers, R., \& Driskell, J. E. (2002). Games, motivation, and learning: A research and practice model. Simulation and Gaming, 33(4), 441-467.

Goodhue, D. L., \& Thompson, R. L. T. (1995). Task-Technology Fit and Individual Performance. MIS Quarterly, 19(2), 213-236. Retrieved from http://www.jstor.org/stable/249689\%5Cnfile://localhost/Users/jiajia/Documents/Referenc e/Papers/MISQuarterly/1995/Goodhue-Task-TechnologyFitandIndividualPerformance.pd f\%5Cnpapers://c2ffaff6-04aa-4ff6-8690-a1c759bfdfcf/Paper/p267

Hakkarainen, K., \& Palonen, T. (2003). Patterns of female and male students' participation in peer interaction in computer-supported learning. Computers \& Education, 40(4), 327-342.

Horvitz, B. S. (2007). N. Dabbagh and B. Bannan-Ritland, Online Learning: Concepts, Strategies, and Application. Educational Technology Research and Development, 55(6), 667-669.

Hulland, J. (1999). Use of partial least squares (PLS) in strategic management research: A review of four recent studies. Strategic Management Journal, 20(2), 195-204.

Iqbal, M. J., \& Ahmad, M. (2010). Enhancing quality of education through e-learning: The case study of Allama Iqbal Open University. Turkish Online Journal of Distance Education, 11(1), 84-97.

Jöreskog, K. G., \& Sörbom, D. (1993). LISREL 8: Structural equation modeling with the SIMPLIS command language. Lawrence Erlbaum Associates, Inc. Retrieved from http://psycnet.apa.org/record/1993-97878-000

Jucks, R., Paechter, M. R., \& Tatar, D. G. (2003). Learning and Collaboration in Online Discourses. International Journal of Educational Policy Research and Practice, 4(1), 117-146.

Kabilan, M. K., Ahmad, N., \& Abidin, M. J. Z. (2010). Facebook: An online environment for learning of English in institutions of higher education? Internet and Higher Education, 13(4), 179-187.

Katz, Y. J. (2000). The Comparative Suitability Of Three ICT Distance Learning Methodologies For College Level Instruction. Educational Media International, 37(1), 25-30.

Katz, Y. J. (2002). Attitudes affecting college students' preferences for distance learning. Journal of Computer Assisted Learning, 18(1), 2-9.

Lai, F., Luo, R., Zhang, L., Huang, X., \& Rozelle, S. (2015). Does computer-assisted learning improve learning outcomes? Evidence from a randomized experiment in migrant schools in Beijing. Economics of Education Review, 47, 34-48.

Liu, C. C., \& Tsai, C. M. (2005). Peer assessment through web-based knowledge acquisition: Tools to support conceptual awareness. Innovations in Education and Teaching International, 42(1), 43-59. 
O'Rourke, N., \& Hatcher, L. (2013). Factor Analysis and Structural Equation Modeling Second Edition-SAS Institute 2013. The Companion to Language Assessment, 1224-1244.

Piccoli, G., Ahmad, R., \& Ives, B. (2001). Web-Based Virtual Learning Environments: A Research Framework and a Preliminary Assessment of Effectiveness in Basic IT Skills Training. MIS Quarterly, 25(4), 401.

Pituch, K. A., \& Lee, Y. K. (2006). The influence of system characteristics on e-learning use. Computers and Education, 47(2), 222-244.

Qureshi, I. A., Ilyas, K., Yasmin, R., \& Whitty, M. (2012). Challenges of implementing e-learning in a Pakistani university. Knowledge Management and E-Learning, 4(3), 310-324.

Rauniar, R., Rawski, G., Yang, J., \& Johnson, B. (2014). Technology acceptance model (TAM) and social media usage: An empirical study on Facebook. Journal of Enterprise Information Management, 27.

Sarwar, B., Zulfiqar, S., Aziz, S., \& Chandia, K. E. (2018). Usage of Social Media Tools for Collaborative Learning: The Effect on Learning Success With the Moderating Role of Cyberbullying. Journal of Educational Computing Research.

Scholle, S. H., Roski, J., Adams, J. L., Dunn, D. L., ..., \& Jensen, R. E. (2008). Benchmarking physician performance: Reliability of individual and composite measures. American Journal of Managed Care, 14(12), 829-838.

Schreiber, J. B., Stage, F. K., King, J., Nora, A., \& Barlow, E. A. (2006). Reporting structural equation modeling and confirmatory factor analysis results: A review. Journal of Educational Research, 99(6), 323-337.

Sun, P. C., Tsai, R. J., Finger, G., Chen, Y. Y., \& Yeh, D. (2008). What drives a successful e-Learning? An empirical investigation of the critical factors influencing learner satisfaction. Computers and Education, 50(4), 1183-1202.

Trentin, G. (1997). Telematics and on-line teacher training: The POLARIS project. Journal of Computer Assisted Learning, 13(4), 261-270.

Tsai, C. C., Lin, S. S., \& Yuan, S. M. (2002). Developing science activities through a networked peer assessment system. Computers \& Education, 38(1-3), 241-252.

Venkatesh, V., \& Davis, F. D. (2016). Studies Linked references are available on JSTOR for this article: A Theoretical Extension of the Technology Acceptance Model. Four Longitudinal Field Studies, 46(2), 186-204.

Venkatesh, V., Morris, M. G., Hall, M., Davis, G. B., Davis, F. D., \& Walton, S. M. (2003). User Acceptance Of Information Technology: Toward A Unified View 1. MIS Quarterly, $27(3), 425-478$.

Wiegel, M., Meston, C., \& Rosen, R. (2005). The Female Sexual Function Index (FSFI): 
Cross-validation and development of clinical cutoff scores. Journal of Sex and Marital Therapy, 31(1), 1-20.

Wu, J., Tsai, R. J., Chen, C. C., \& Wu, Y. (2006). An Integrative Model to Predict the Continuance Use of Electronic Learning Systems: Hints for Teaching. International Journal on E-Learning, 5(2), 287-302.

\section{Appendix 1: Questionnaire items and sources}

Peer interaction (Arbaugh, 2002)

PI 1. Student-to-student interaction was more difficult than in other courses.

PI 2. Class discussions were more difficult to participate in than other courses.

PI 3. I learned more from my fellow students in this class than in other courses.

PI 4. The instructor frequently attempted to elicit student interaction.

PI 5. Interacting with other students and the instructor using a web-based learning system became more natural as the course progressed.

PI 6. I felt that the quality of class discussions was high throughout the course.

PI 7. It was easy to follow class discussions

PI 8. Classroom dynamics were not much different than in other courses.

PI 9. Once we became familiar with the web-based learning system, it had very little impact on the class.

(Likert's scale 1, strongly agree; 7, strongly disagree)

Perceived usefulness (Arbaugh, 2002; Sarwar et al., 2018; Sun et al., 2008)

PU 1. Using web-based learning system would enhance my effectiveness in my coursework.

PU 2. Using web-based learning system would improve my performance in my coursework

PU 3. I would find web-based learning system useful in my coursework

PU 4. Using web-based learning system in my coursework would enhance my Productivity.

(Likert's scale 1, strongly agree; 7, strongly disagree)

Perceived ease of use (Arbaugh, 2002; Sarwar, Zulfiqar, Aziz, \& Chandia, 2018; Sun, Tsai, Finger, Chen, \& Yeh, 2008)

PEU 1. Learning to operate web-based learning systems is easy for me

PEU 2. I find it easy to get a web-based learning system to do what I want it to do

PEU 3. I find web-based learning systems easy to use 
PEU 4. It is easy for me to become skillful at using web-based learning systems

Virtual learning (Pituch \& Lee, 2006; Venkatesh \& Davis, 2016)

VL 1. Using the e-learning system enables me to accomplish tasks more quickly.

VL 2. Using the e-learning system improves my performance

VL 3. Using the e-learning system increases my productivity

VL 4. Using the e-learning system enhances the effectiveness on the job

VL 5. Using the e-learning system makes it easier to do my learning

VL 6. Using the e-learning system gives me greater control over my work.

(Likert's scale 1, strongly agree; 7, strongly disagree)

Learner Satisfaction (Arbaugh, 2002; Sun et al., 2008)

LS 1. I am satisfied with the use of e-learning in my course-work

LS 2. If I had an opportunity to use e-learning in any other coursework, I would gladly do so

LS 3. My choice to use e-learning in this coursework was a wise one

LS 4. I was very satisfied with the e-learning

LS 5. I feel that this coursework served my needs well.

LS 6. I will use e-learning in many courses as I can

LS 7. I was disappointed with the way this course work worked out.

LS 8. If I had it to do over, I would not use e-learning in this course work

LS 9. Conducting the course via e-learning made it more difficult than other in course works I have taken

(Likert's scale 1, strongly agree; 7, strongly disagree)

\section{Copyright Disclaimer}

Copyright reserved by the author(s).

This article is an open-access article distributed under the terms and conditions of the Creative Commons Attribution license (http://creativecommons.org/licenses/by/3.0/). 